\title{
COAL STRUCTURAL CHARACTERISTICS OF BAYAH FORMATION BASED ON X-RAY DIFFRACTION ANALYSIS
}

\author{
Ahmad Helman Hamdani ${ }^{1 凹}$ (D), Agus Didit Haryanto ${ }^{1}$ (D), Muhamad Iqbal ${ }^{1}$ (D) \\ ${ }^{1}$ Department of Geology, University of Padjadjaran, Indonesia
}

Received 06 January 2022

Accepted 12 February 2022

Published 28 February 2022

\section{CorrespondingAuthor}

Ahmad Helman Hamdani, ahmad.helman@unpad.ac.id

DOI

10.29121/granthaalayah.v10.i2.2022 .4495

Funding: This research received no specific grant from any funding agency in the public, commercial, or not-for-profit sectors.

Copyright: (C) 2022 The Author(s). This is an open access article distributed under the terms of the Creative Commons Attribution License, which permits unrestricted use, distribution, and reproduction in any medium, provided the original author and source are credited.

\section{ABSTRACT}

The coal of Bayah Formation in Lebak Regency, Indonesia have been subjected to attenuated to X-ray diffraction (XRD), to study their chemical and structural characteristics. X-Ray Diffraction (XRD) has been widely used throughout the world and has high accuracy in identifying the molecular structure of coal. Curve-fitting analysis was employed to characterize coal structural. Based on ASTM, the coal rank from this area is high-volatile bituminous B. The research results show all coals have the similar coal structural crystallite characteristics. The value of $\mathrm{d}_{002}$ is in the range of 3.87 to 3.96, reflecting the coals have a low content of crystalline structure. The crystallite height (Lc) and diameter (La) were increase, while dooz decrease in relation of more mature coals. Due to structural parameters ( $\mathrm{d}_{002}$, Lc and La) the coals of Bayah Formation dominantly by disordered amorphous structure, with small amount crystallite structure.

Keywords: Coal, Structural, XRD, Curve Fitting, Bayah Formation

\section{INTRODUCTION}

During coalification process, various kinds of inorganic, organic and water materials are involved together, so coal is heterogeneous; and provides diverse physical and chemical characteristics which are reflected in the values of the heterogeneous crystalline structural parameters in coal. Therefore, study on the crystal coal structure is important; with knowledge of molecular structure of coals; physicochemical reactions during the coal combustion, gasification, and pyrolysis can be controlled. Singh et al. (2015), Sonibare et al. (2010), Saikia et al. (2007).

XRD is a non-damage method that is often used to study the crystallite structural of materials containing carbon, such as coal Haenel (1992), Lu et al. (2001), Vivek et al. (2016). Several indicators of crystal structure in coal measured by XRD are stacking height of crystallite (Lc), average lateral sizes (La), interlayer spacing of the crystalline structure (d002), aromaticity (fa). The coal rank was controlled the development of coal crystal structure parameter. An increase in coal maturation will be followed by a decrease in the value of $\mathrm{d} 002$, and an increase in the value of La and Lc, but the value of Lc gradually decreasing. In the throughout the coalification process, an increase crystal structure of coal and a decrease in the amorphous structure Jiang et al. (2019). Hirsch (1979), Watanabe et al. (2002). Qualitatively, the structure in coal generally consists of crystalline carbon and amorphous carbon Lu et al (2015). In Banten Province the 
occurrence of coal is reported found within Bayah Formation of Eocene strata Sujatmiko and Santosa (1992) Investigation of the Bayah Formation coal was limited to the analysis of proximate, ultimate and maceral compositions. However, research on the structure of coal has not been investigated. The aim of this research is the use of XRD technique to study the structural characteristics of the Bayah Formation coal.

\section{MATERIALS AND METHODS 2.1. SAMPLE AND SAMPLE PREPARATION}

Five bituminous coals from Bayah Formation, Banten Province were selected for this investigation. Several analyses were carried out to obtain the chemical molecular structure characteristics of bituminous coal, such as proximate, ultimate, XRD analysis.

\subsection{EXPERIMENTAL METHODS}

Proximate, Ultimate Analysis. The series measurement of moisture, ash, fixed carbon, and volatile matter in coal which is grouped in Proximate Analysis. The ASTM Standard of moisture, ash, fixed carbon, volatile matter was used, such as D3173, D-3174, D-388, D-3175, respectively. The ultimate analysis was measured carbon and hydrogen, nitrogen, sulphur, and oxygen based on ASTM Standard of ASTM D-3178, ASTM D-3179, ASTM D-3177, and ASTM D-3176, respectively. The result of all analysis was presented in Table 1.

$X R D$. An X-ray diffractometer device (BrukerAXSD8) was used to obtain the spectral characteristics of the XRD. The operational conditions used are as follows: $\mathrm{CuKa}$ radiation $(40 \mathrm{Kv}, 40 \mathrm{~mA})$ in the angular range of $100-800(2 \theta)$ with 0.020 step interval and a scanning rate of increments from 50 to $900(2 \theta)$ at intervals of 0.02 and counted for $0.5 \mathrm{sec}$ per step. The Bragg's and Scherrer equations were used calculated the structural parameters Equation 1, Equation 2, Equation 3, Equation 4 Equation 5, Iwashita et al. (2004), Okolo et al (2010), Robert et al. (2015), Baysal et al. (2016), Li et al. (2013), Li and Zhu (2014)

$$
\begin{aligned}
& \mathrm{fa}=\operatorname{Car} /(\mathrm{Car}+\mathrm{Cal})=\mathrm{A}_{002} /\left(\mathrm{A}_{002}+\mathrm{Ay}\right) \\
& \mathrm{d} 002=\frac{\lambda}{2 \sin \theta 002} \\
& \mathrm{La}=1.84 \lambda /\left(\beta_{002} \cos \Theta_{002}\right) \\
& \mathrm{Lc}=0.89 \lambda /\left(\beta_{100} \cos \Theta_{100}\right) \\
& \mathrm{N}=\frac{\mathrm{Lc}}{\mathrm{d} 002}
\end{aligned}
$$

Equation 1

Equation 2

Equation 3

Equation 4

Equation 5

Where Car is the sum of the aromatic carbons, and the value of Cal is the sum of the aliphatic carbons. $A_{002}$ and $A_{y}$ are areas of peak 002 and peak $y$ which are around the $26^{\circ}$ and $20^{\circ} \mathrm{x}$ coordinates respectively on the XRD graph. $\lambda=1.54056$ for copper Ka radiation; $\lambda$ is the wavelength of the radiation used. $\theta_{002}$ and $\theta_{100}$ are the diffraction angles from peak 002 and peak 100. $\beta_{002}$ and $\beta_{100}$ are full width half at maximum values (FWHM) of peak 002 and peak 100. 
To determine coal rank from XRD from the formula Equation 6, Yoshizawa et al. (2002)

Coal rank $=\left(\mathrm{I}_{26} / \mathrm{I}_{20}\right)$

Equation 6

\section{RESULTS AND DISCUSSIONS}

\subsection{PROXIMATE AND ULTIMATE ANALYSIS}

Result of analysis of Bituminous coals from Bayah Formation, Banten Province was shown in Table 1 . The average atomic ratios of $\mathrm{H} / \mathrm{C}, \mathrm{O} / \mathrm{C}$, were calculated to be $0.86,0.08$, respectively. The moisture is low in all coals (1.8-2.4wt\%), and low ash yield (, 5\% wt.\%). The coals have a high volatile matter, and fixed carbon, i.e., $45.7 \%$ to $46.1 \%, 47.5 \%$ to $51.1 \%$., respectively. The sulfur in samples is low $(0.76-n 1.21$ wt.\%). Measurement of C-H-O elements in coals showed that the carbon content was very high, which was followed by oxygen and hydrogen as presented in Table 1.

\begin{tabular}{|ccccccc}
\hline \multicolumn{5}{|c}{ Table 1 Result of proximate and ultimate measurement of coal samples } \\
\hline & Parameters & ST-11.2 & ST-14 & ST-17 & ST-21 & ST-24 \\
\hline \multirow{2}{*}{ Proximate (ad) } & Moisture & 4,13 & 4.21 & 4.73 & 3.92 & 4.28 \\
\cline { 2 - 7 } & Ash & 5.81 & 4.21 & 3.78 & 2.61 & 2.17 \\
& Volatile Matter & 39.31 & 40.12 & 41.42 & 42.18 & 42.51 \\
\hline \multirow{2}{*}{ Ultimate (daf) } & Fixed Carbon & 50.75 & 51.46 & 50.07 & 51.29 & 51.03 \\
& Carbon & 79.64 & 78.49 & 80.05 & 78.43 & 78.34 \\
\hline & Hydrogen & 3.35 & 4.19 & 4.2 & 4.54 & 5.23 \\
\hline H/C & Oxygen (by diff) & 15.31 & 14.82 & 14.4 & 16.18 & 15.44 \\
\hline O/C & & 0.5 & 0.64 & 0.62 & 0.69 & 0.8 \\
\hline
\end{tabular}

\subsection{XRD}

In the XRD graph Figure 1, it is clear that the peaks of XRD spectral intensity of 002,10 , and 100 are identified. These three peaks are at diffraction degrees of $2 \theta$ at $26^{\circ}, 42^{\circ}$ and $47^{\circ}$, respectively. In addition, to the left of peak $\gamma$ is identified peak, both of which are Gaussian peaks.

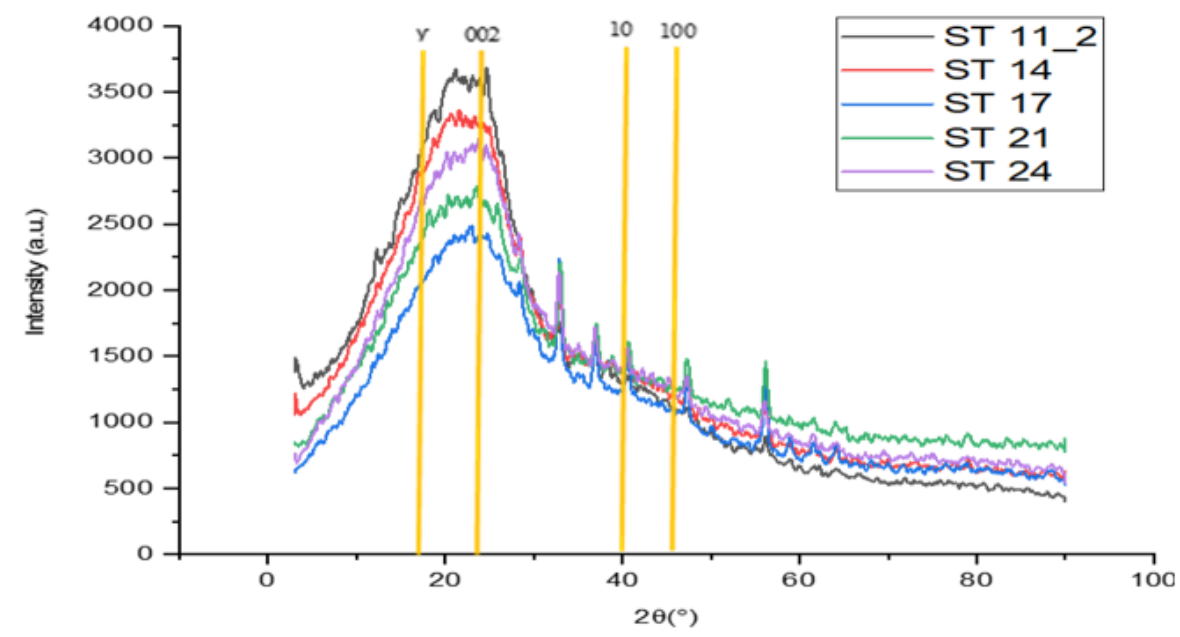

Figure 1 XRD spectra of Bayah coal samples 
To get the peak area, diffraction angle 20, intensity value and FWHM (Full Width Half Maximum) value; Curve fitting analysis (Gaussian method) was performed on all coal samples. Figure 2 shows the results of the Curve fitting sample no. ST. 17, and ST. 21, which represents all coal samples. Table 2 tabulated the results of the calculation of the structural parameters of coal with the XRD method of Bayah Formation coal
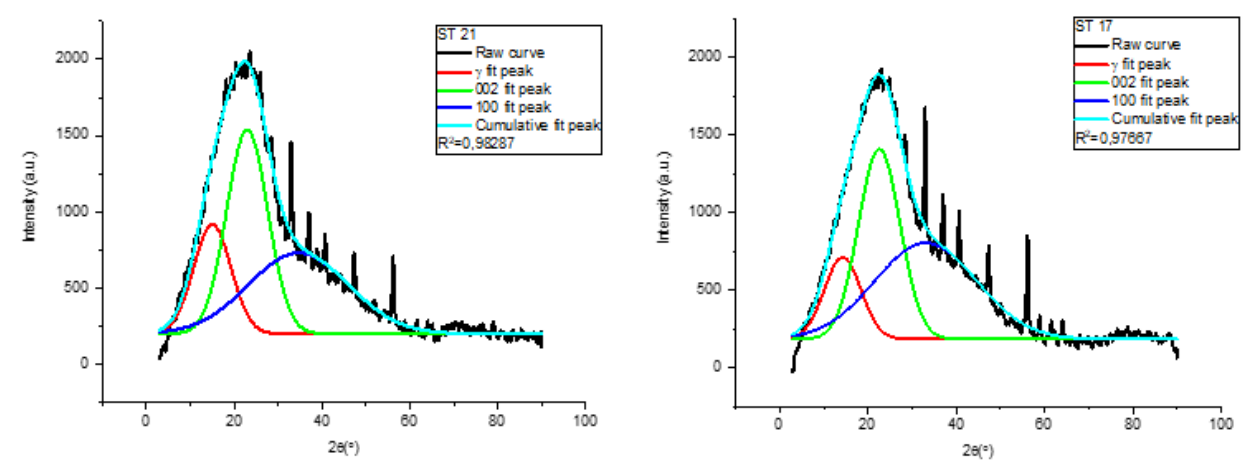

Figure 2 Gaussian's curve fitting XRD Spectral from coal samples of Bayah Formation

Table 2 Structural parameters of coal by XRD

\begin{tabular}{|c|c|c|c|c|c|c|c|c|}
\hline Sample & $\mathbf{d}_{002}(\AA)$ & La $(\AA ీ)$ & Lc $(\AA \overline{)})$ & fa & $\mathbf{N}$ & n2 & $\mathbf{I}_{26} / \mathrm{I}_{20}$ & Ro (\%) \\
\hline ST 11_2 & 3.96 & 15.3 & 7.3 & 0.76 & 2.85 & 2.61 & 2.61 & 0.72 \\
\hline ST 14 & 3.94 & 13.16 & 5.81 & 0.64 & 2.49 & 1.98 & 2.01 & 0.71 \\
\hline ST 17 & 3.94 & 14.9 & 3.01 & 0.73 & 1.76 & 1 & 1.98 & 0.68 \\
\hline ST 21 & 3.86 & 15 & 3.12 & 0.67 & 1.79 & 1.03 & 1.69 & 0.74 \\
\hline ST 24 & 3.91 & 14.1 & 3.31 & 0.68 & 1.84 & 1.09 & 1.93 & 0.65 \\
\hline
\end{tabular}

Where:

D002: Interlayer spacing

Lc: Crystallite height

La: Crystallite diameter

I26/I20: Coal rank

From the results of measurement of coal structural parameters by XRD analysis Table 2, it can be seen that the value of the interlayer distance $\left(\mathrm{d}_{002}\right)$ is in the range of 3.86 to $3.96 \AA$, the average diameter of crystallite (La) is in the diameter of 13.16 to $15.30 \AA$, the average size of crystallite height is (Lc) in the range 3.01 to $7.30 \AA$, carbon aromaticity ( $\mathrm{fa}$ ) in the range 0.64 to 0.76 , coal $\operatorname{rank}\left(\mathrm{I}_{26} / \mathrm{I}_{20}\right)$ in the range 1.69 to 2.61 , and carbon layer $(\mathrm{N})$ in the range of 1.76 to 2.85 , and the value of $n$ is between $1.00-2.61$.

\section{DISCUSSION}

Based on the analysis of proximate and ultimate analysis; ratio of $\mathrm{H} / \mathrm{C}$ and $\mathrm{O} / \mathrm{C}$ indicated that all coals were classified as the High Volatile Bituminous-B coal.

The results of the observation of coal XRD spectral peaks show that peak 002 is higher compared to peak 10 or 100; apart from structured; it was clearly found at $26^{\circ}, 42^{\circ}$ and $47^{\circ}$, respectively. Generally, in coals the XRD spectral consists of 002 and 100 peaks, which peak 002 has the position in areas between $15-30^{\circ}$ : and peak 
100 in the range of $40-50^{\circ}$. Smędowski et al. (2011), Baysal et al. (2016). This reflects that the coal studied have a structure like graphite (crystallite carbon). However, with the high detected background, the coal also contains an amorphous material structure (highly disordered materials). Therefore, based on the appearance of the peak of the spectral XRD; Therefore, Bayah coal is composed of amorphous and crystalline material Lu et al. (2001), Okolo et al. (2015).

The values of coal crystallite structures such as $\mathrm{d}_{002}$, La, and has a relation with coal maturity (\%Ro). For all the coal samples were shown that with an increase of $\% R_{0}$, the variation of $L_{\mathrm{a}}$ increase slightly for coal from $13.16-15.30 \AA \mathrm{A}^{\prime} \mathrm{d}_{002}$ decrease slightly of 3.86-3.96 ̊́, while Lc decreasing from 3.91 - $3.86 \AA$. In high rank coal, graphite structure is more likely to form compared than in low rank coal. The interlayer distance $\left(\mathrm{d}_{002}\right)$ in all samples showed a higher range (3.86 to $3.96 \AA$ ) than $\mathrm{d}_{002}$ pure graphite $\left(\mathrm{d}_{002}=3.36-3.37 \AA\right)$, reflecting the low degree of crystal regularity in coals. Bhupati et al (2017).

The interlayer spacing $\left(\mathrm{d}_{002}\right)$ in the high mature bituminous coal $(\mathrm{Ro}=0.74 \%)$ of the Bayah Formation was small (3.86 $\AA$ ); associated with a lower carbon element content value (79-80\%) compared to that contained by pure graphite Singh et al. (2015), Singh et al (2017). Besides that, it is also related to the aromatic ring in the coal continues to solidify as the coal matures.

Overall, the findings in this study indicate that the more mature (high \%Ro), the smaller the amorphous structure, which is followed by an increase in crystallite height and diameter; but the interlayer spacing is getting smaller. The same finding was also conveyed by other researchers. Shike et al. (2021), Takagi et al. (2004)

\section{CONCLUSIONS AND RECOMMENDATION}

A total of 5 coal sample from Bayah Formation, Indonesia have been identified the structural characteristic based on XRD measurement. Following conclusion are drawn:

1) The coals are classified as the High Volatile Bituminous $B$

2) The XRD investigations show the highly disordered amorphous and crystallite structure were identified in coals.

3) The crystalline carbon in coals having the sizes of La, (Lc), and $\mathrm{d}_{002}$ ranging from $13.16-15.30 \AA \AA, 3.01$ to $7.30 \AA ̊$, and 3.86 to $3.96 \AA$, respectively.

We, recommend XRD study to be used to indicate coal maturity level

\section{ACKNOWLEDGEMENTS}

The authors would like to expression of gratitude was conveyed to the Chancellor of the University of Padjajaran who has funded this research through the 2021 ALG scheme.

\section{REFERENCES}

Baysal, M., Yürüm, A., Yıldız, B., Yürüm, Y. (2016) Structure of some western Anatolia coals investigated by FTIR, Raman, 13C solid state NMR spectroscopy and Xray diffraction. Int. J. Coal. Geol., 163, : 166- 176, DOI : 10.1016/j.coal.2016.07.009 Retrieved from https://doi.org/10.1016/j.coal.2016.07.009

Dun, W., and Wenyong, Z. (2019) Evolution Mechanism of Macromolecular Structure in Coal during Heat Treatment : Based on FTIR and XRD In Situ 
Analysis Techniques. Journal of Spectroscopy, 2019, : 1-18. Retrieved from https://doi.org/10.1155/2019/5037836

Everson, R. C., Okolo, G. N., Neomagus, H. W. J. P., (2013) Dos Santos, J. M. X-ray diffraction parameters and reaction rate modeling for gasification and combustion of chars derived from inertinite-rich coals. Fuel, 109, : 148-156, DOI : $\quad 10.1016 /$ j.fuel.2012.12.043 Retrieved from https://doi.org/10.1016/j.fuel.2012.12.043

Haenel, M. W. (1992) : Recent progress in coal structure research. Fuel, 71, : 12111223 Retrieved from https://doi.org/10.1016/0016-2361(92)90046-Q

Hattingh, B. B., Everson, R. C., Neomagus, H. W. J. P., Bunt, J. R., van Niekerk, D., Jordaan, J. H. L., Mathews, J. P. (2013) Elucidation of the Structural and Molecular Properties of Typical South African Coals. Energy Fuels 27, : 31613172, DOI : 10.1021/ef400633d Retrieved from https://doi.org/10.1021/ef400633d

Hirsch, P. B. (1979) Recent results on the structure of dislocations in tetrahedrally coordinated semiconductors," Le Journal de Physique Colloques, 40(6), : 627. Retrieved from https://doi.org/10.1051/jphyscol:1979606

Iwashita, N., Park, C. R., Fujimoto, H., (2004) Specification for a standard procedure of X-ray diffraction measurements on carbon materials. Carbon 42, : 701714 Retrieved from https://doi.org/10.1016/j.carbon.2004.02.008

Jiang, J., Yang, W., Cheng, Y., Liu, Z., Zhang, Q. (2019) Molecular structure characterization of middle-high rank coal via XRD, Raman and FTIR spectroscopy : Implications for coalification. Fuel 239, : 9-572 Retrieved from https://doi.org/10.1016/j.fuel.2018.11.057

Li, M., Zeng, F., Chang, H., Xu, B., Wang, W. (2013) Aggregate structure evolution of low-rank coals during pyrolysis by in-situ X-ray diffraction. Int. J. Coal Geol. 116-117, : 262- 269, DOI : 10.1016/j.coal.2013.07.008 Retrieved from https://doi.org/10.1016/j.coal.2013.07.008

Li, W., Zhu, Y. (2014) Structural Characteristics of Coal Vitrinite during Pyrolysis. Energy Fuels, 28, : 3645- 3654, DOI : 10.1021/ef500300r Retrieved from https://doi.org/10.1021/ef500300r

Lu, L., Sahajwalla, V., Kong, C., Harris, D. (2001) Quantitative X-ray diffraction analysis and its application to various coals. Carbon, : 1821-1833. DOI : 10.1016/S0008-6223(00)00318-3 Retrieved from https://doi.org/10.1016/S0008-6223(00)00318-3

Okolo, G. N., Neomagus, H. W., Everson, R. C. (2015) Chemical-structural properties of South African bituminous coals : insights from wide angle XRD - carbon fraction analysis, ATR-FTIR, solid state 13CNMR, and HRTEM techniques. Fuel 158, : 779-792. DOI : 10.1016/j.fuel.2014.10.046 Retrieved from https://doi.org/10.1016/j.fuel.2014.10.046

Robert, s M. J., Everson, R.C., Neomagus, H. W. J. P., Okolo, G.N., Niekerk, D.V., Mathews, J. P., (2015) The characterization of slow-heated inertinite-and vitrinite-rich coals from the South African coalfields. Fuel 158, :591-601. DOI : 10.1016/j.fuel.2014.10.033 Retrieved from https://doi.org/10.1016/j.fuel.2014.10.033

Saikia, B. K., Boruah, R. K., Gogoi, P. K., C., (2007) XRD and FTIR investigations of subbituminous Assam coals. Bulletin Material Science 30(4), :421-426. DOI : 10.1007/s12039-009-0012-0 Retrieved from https://doi.org/10.1007/s12039-009-0012-0 
Shike, L., Yanming, Z., Yang, W., Jing, L. (2021) The Chemical and Alignment Structural Properties of Coal : Insights from Raman, Solid-State 13C NMR, XRD, and HRTEM Techniques. ACS Omega 6 (17), :11266-11279 DOI : 10.1021/acsomega.1c00111 Retrieved from https://doi.org/10.1021/acsomega.1c00111

Singh, A. L., Singh, P. K, Kumar, A. (2015) Demineralization of Rajmahal Gondwana coals by bacteria: revelations from X-ray diffraction (XRD) and Fourier transform infra-red (FTIR) studies, Energy Exploration Exploit. 33(5) : : 755-767. Retrieved from https://doi.org/10.1260/0144-5987.33.5.755

Smędowski, Ł., Krzesińska, M., Kwaśny, W., Kozanecki, M. (2011) Development of Ordered Structures in the High-Temperature (HT) Cokes from Binary and Ternary Coal Blends Studied by Means of X-ray Diffraction and Raman Spectroscopy. Energy Fuels 25, :3142- 3149, DOI : 10.1021/ef200609t Retrieved from https://doi.org/10.1021/ef200609t

Sonibare, O. O., Haeger, T., Foley, S. F. (2010) : Structural characterization of Nigerian coals by X-ray diffraction, Raman and FTIR spectroscopy. Energy 35, : 53475353. DOI : 10.1016/j.energy.2010.07.025 Retrieved from https://doi.org/10.1016/j.energy.2010.07.025

Takagi, H. ; Maruyama, K. ; Yoshizawa, N. ; Yamada, Y. ; Sato, Y. (2004) XRD analysis of carbon stacking structure in coal during heat treatment. Fuel 83, : 24272433, DOI : 10.1016/j.fuel.2004.06.019 Retrieved from https://doi.org/10.1016/j.fuel.2004.06.019

Vivek, M., Mamta, S., Sanchita, C., Amit. B. (2016) Changes in organic structure and mineral phases transformation of coal during heat treatment on laboratory scale. Int. J. Coal. Sci. Technol. 3(4), :418-428. DOI 10.1007/s40789-0160153-y Retrieved from https://doi.org/10.1007/s40789-016-0153-y

Watanabe, I., Sakanishi, K., Mochida, I., Akimoto, A. (2002) Changes in coal aggregate structure by heat treatment and their coal rank dependency, Energy \& Fuels, 16 (1), : 18-22, 2002 Retrieved from https://doi.org/10.1021/ef010144e

Yoshizawa, N., Maruyama, K., Yamada, Y., et al. (2002) XRD evaluation of KOH activation process and influence of coal rank. Fuel 81, : 1717-1722 Retrieved from https://doi.org/10.1016/S0016-2361(02)00101-1 